\title{
Social desirability, environmental attitudes and general ecological behaviour in children
}

\author{
Oerke, B ; Bogner, F X
}

\begin{abstract}
Socially desirable responses have been widely discussed as potentially biasing self-reported measures of environmental attitude and behaviour assessment. The direct and moderating effect of social desirability on children has not been analysed before. By applying a Lie scale together with a two-factor environmental attitude set measure and a scale of self-reported General Ecological Behaviour (GEB) to 198 pupils, we found a moderate impact of Lie scores on only one of both attitude measures and a small impact on GEB. In a multiple regression analysis general behaviour was predicted by attitude, social desirability, and the interaction of both. Social desirability had no moderating effect on the relationship between environmental attitudes and behaviour. Implications of these outcomes for research on environmental issues with children are discussed.
\end{abstract}

DOI: https://doi.org/10.1080/09500693.2011.566897

Posted at the Zurich Open Repository and Archive, University of Zurich ZORA URL: https://doi.org/10.5167/uzh-55025

Journal Article

Published Version

Originally published at:

Oerke, B; Bogner, F X (2011). Social desirability, environmental attitudes and general ecological behaviour in children. International Journal of Science Education, 33:online.

DOI: https://doi.org/10.1080/09500693.2011.566897 
This article was downloaded by: [Universitaet Zurich]

On: 11 January 2012, At: 01:54

Publisher: Routledge

Informa Ltd Registered in England and Wales Registered Number: 1072954 Registered

office: Mortimer House, 37-41 Mortimer Street, London W1T 3JH, UK

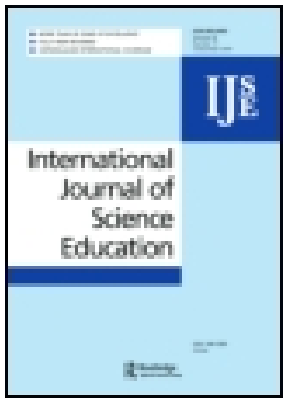

\title{
International Journal of Science Education
}

Publication details, including instructions for authors and subscription information:

http:/ / www.tandfonline.com/loi/tsed20

\section{Social Desirability, Environmental Attitudes, and General Ecological Behaviour in Children}

\author{
Britta Oerke ${ }^{a}$ \& Franz X. Bogner ${ }^{a}$ \\ a Department of Biology Didactics, Centre of Math and Science \\ Education, University of Bayreuth, Bayreuth, Germany
}

Available online: 01 Jun 2011

To cite this article: Britta Oerke \& Franz X. Bogner (2011): Social Desirability, Environmental Attitudes, and General Ecological Behaviour in Children, International Journal of Science Education, DOI:10.1080/ 09500693.2011.566897

To link to this article: http:// dx.doi.org/ 10.1080/ 09500693.2011.566897

\section{Girst}

\section{PLEASE SCROLL DOWN FOR ARTICLE}

Full terms and conditions of use: http://www.tandfonline.com/page/terms-andconditions

This article may be used for research, teaching, and private study purposes. Any substantial or systematic reproduction, redistribution, reselling, loan, sub-licensing, systematic supply, or distribution in any form to anyone is expressly forbidden.

The publisher does not give any warranty express or implied or make any representation that the contents will be complete or accurate or up to date. The accuracy of any instructions, formulae, and drug doses should be independently verified with primary sources. The publisher shall not be liable for any loss, actions, claims, proceedings, demand, or costs or damages whatsoever or howsoever caused arising directly or indirectly in connection with or arising out of the use of this material. 


\title{
Social Desirability, Environmental Attitudes, and General Ecological Behaviour in Children
}

\author{
Britta Oerke* and Franz X. Bogner \\ Department of Biology Didactics, Centre of Math and Science Education, University of \\ Bayreuth, Bayreuth, Germany
}

\begin{abstract}
Socially desirable responses have been widely discussed as potentially biasing self-reported measures of environmental attitude and behaviour assessment. The direct and moderating effect of social desirability on children has not been analysed before. By applying a Lie scale together with a two-factor environmental attitude set measure and a scale of self-reported General Ecological Behaviour (GEB) to 198 pupils, we found a moderate impact of Lie scores on only one of both attitude measures and a small impact on GEB. In a multiple regression analysis general behaviour was predicted by attitude, social desirability, and the interaction of both. Social desirability had no moderating effect on the relationship between environmental attitudes and behaviour. Implications of these outcomes for research on environmental issues with children are discussed.
\end{abstract}

Keywords: Social desirability; Ecological behaviour; Environmental attitudes

\section{Introduction}

A valid measurement of environmentally relevant attitudes and behaviours is essential to seriously validate and evaluate environmental education programmes for children and adolescents. Several authors, however, have criticised a lack of concern with the establishment of valid instruments (Bogner \& Wiseman, 2006; Leeming, Dwyer, Porter, \& Cobern, 1993). A threat to the validity of self-report measures is Social Desirability Bias (SDB) (e.g. Bogner \& Wiseman, 2006; Mummendey, 1981). It may cause a major problem because eco-friendly attitudes and behaviour can be considered a social norm (Newhouse, 1990). This social norm may lead to a

\footnotetext{
*Corresponding author. Now at: Institute of Education, University of Zurich, Freiestrasse 36, 8032 Zurich, Switzerland. Email: b.oerke@ife.uzh.ch
} 
general inflation of measured attitude and behaviour scores and may even impact on the relationship between them.

In this present study, we coped with these problems in the age group of adolescents in the frame of an environmental education study by means of measurement instruments developed exclusively for that age group.

\section{Measurement of Environmental Attitudes}

The construct of Environmental Attitudes (EA) commonly refers to a multiple component approach, for example in a recent definition provided by Schultz, Shriver, Tabanico, and Khazian (2004), to 'the collection of beliefs, affect, and behavioural intentions a person holds regarding environmentally related activities or issues' (p. 31).

Various approaches have been presented in operationalising empirical scales within the domain of EA (cf. Bogner \& Wiseman, 2002), measuring attitudes on different levels of specificity (attitudes, world views, values). The factor-analytic dimensionality of these instruments depends to a great extent on the item-pool it is based on, ranging from one-dimensional scales, for example the New Environmental (Ecological) Paradigm (NEP) Scale (Dunlap \& Van Liere, 1978; Dunlap, Van Liere, Mertig, \& Jones, 2000; Milfont \& Duckitt, 2004), to two (an anthropocentric and an ecocentric view, Gagnon Thompson, \& Barton, 1994), or three or even more (e.g. Stern, Dietz, \& Guagnano, 1995). Using higher-order factor analysis on the basis of a large pool of items, Bogner and Wiseman (1999; Wiseman \& Bogner, 2003) produced a higher-order two-factor model of Environmental Values that has been replicated by Milfont and Duckitt (2004, 2006). The term 'value' is employed following a convention established by Rokeach $(1968,1973)$ to indicate a set of closely related attitudes: first-order factors are labelled 'attitudes', higher order factors 'values'. Two secondorder factors were extracted: Preservation $(\mathrm{P})$, a bio-centric dimension that reflects conservation and protection of the environment, and Utilisation (U), an anthropocentric dimension reflecting the utilisation of natural resources (Wiseman \& Bogner, 2003). The model defines the factors $P$ and $U$ are orthogonal, allowing a person both to endorse the protection of the environment $(\mathrm{P})$ and to support the usage of nature (U). In practice, Wiseman and Bogner (2003), using oblique rotation, reported a low negative correlation of -0.17 . Since this explains less than $3 \%$ of the variance, these authors regard this as of negligible substantive importance.

In this present study we applied the latest version of Bogner and Wiseman (2006), since it represents the only instrument for quantifying environmental views developed and validated for the age-group of adolescents (Bogner \& Wiseman, 1999, 2002, 2006).

\section{Measurement of Ecological Behaviour}

One reason for the importance of measuring EA is the expectation of obtaining a valuable predictor of ecological behaviour. Empirical results on the relationship of EA to behaviour, however, are inconsistent: Correlations vary from weak (e.g. Diekmann \& Preisendörfer, 1998; Scott \& Willits, 1994; Van Liere \& Dunlap, 1981) 
via moderate $(22 \%$ of explained variance for adolescents, Meinhold \& Malkus, 2005 ) to strong (about $40 \%$ of explained variance, Weigel \& Weigel, 1978), with an average corrected ${ }^{1}$ correlation in the meta-analysis of Hines, Hungerford, and Tomera (1987) of $r=0.35$ and of $r=0.42$, respectively, in the meta-analysis of Bamberg and Möser (2007). At least three aspects of measurement explain the variation in the interrelationships between $\mathrm{EA}$ and behaviour.

Lack of measurement correspondence. First, a lack of measurement correspondence between both measures will probably reduce attitude-behaviour consistency (Ajzen \& Fishbein, 1977). This is the case if ecological behaviour is measured at a specific level, for example in form of independent concepts like recycling or consumerism (for a review see Kaiser, 1998), whereas EA is measured on a general level, as in the popular NEP Scale (Dunlap \& Van Liere, 1978). We find examples of both low correlations in studies with low measurement correspondence (e.g. Diekmann \& Preisendörfer, 2003; Weigel \& Weigel, 1978), and higher correlations in studies with high measurement correspondence (Newhouse, 1990).

Impact of situational factors. Second, external conditions on ecological behaviour will reduce behaviour consistency and the relationship to EA. Situational factors make behaviours easier or more difficult to carry out and thus impact on the frequency of behaviour execution (Diekmann \& Preisendörfer, 2003; Kaiser, 1998). The number of bottle banks in a city, for example, will affect the glass recycling rate, though the people of this city are no more concerned about the environment than others. Consequently, inconsistency in ecological acts is dependent on behaviour difficulty (e.g. Diekmann \& Preisendörfer, 1998; Granzin \& Olsen, 1991). In a probabilistic measurement approach, people are allowed to choose between different ecological acts of different difficulty. The Rasch model (see Bond \& Fox, 2007) is a probabilistic measurement model that predicts the probability of a specific type of behaviour with a given difficulty to be carried out by a specific person with a given tendency to behave ecologically (Kaiser, 1998).

In the present study, we used the General Ecological Behaviour (GEB) scale for adolescents (Kaiser, Oerke, \& Bogner, 2007). As a self-report instrument asking for a great variety of different acts, it measures reported behaviour at a general level in the same manner as the attitude scales applied, and thus assures measurement correspondence (a). Calibrated as a Rasch scale, it further provides a solution for the problems caused by situational factors (b). The scale was adapted from an instrument for adults developed by Kaiser and co-workers (Kaiser, 1998; Kaiser \& Wilson, 2004; Kaiser, Wölfing, \& Fuhrer, 1999).

Social desirability. The third reason for low EA and behaviour relationship is 'socially acceptable' responding to either the behaviour or to the attitude test items. This latter aspect of measurement will be analysed in this paper. 


\section{Measurement of the Social Desirability Bias (SDB)}

Although self-reporting allows measurement of a wide range of actions, it has been criticised for being susceptible to measurement bias (e.g. Diekmann \& Preisendörfer, 2003; Mummendey, 1981), for example $S D B$, the tendency 'to give overly positive self-descriptions' (Paulhus, 2002, p. 50). In personality research, SDB has been shown to be a personal response style that can be measured with a Lie scale (e.g. Crowne \& Marlow, 1964). Early Lie scales, developed to detect more or less conscious lying within personality questionnaires, asked for socially undesirable common and uncommon behaviour: such scales were regarded as one-dimensional. A two-dimensional approach to SDB has been employed by a number of authors using factor analysis (e.g. Sackeim \& Gur, 1979) and as an elaborated two-factor model presented by Paulhus (1984, 2002). He distinguished between self-deceptive enhancement, representing an unconscious tendency to perceive reality optimistically biased as some form of self-protection; and impression management, a deliberate deception to impress an audience, for example an interviewer. The latter aspect of SDB corresponds to the classic Lie scales.

Another method of measuring SDB is that of rating the items of interest with respect to social desirability by experts (e.g. Schahn, 2002) or by the subjects themselves.

Social desirability scales for children. We are aware of only two scales systematically constructed to measure SDB in children, both uni-dimensional: The Children's Social Desirability scale (Crandall, Crandall, \& Katkovsky, 1965), consisting of 48 items, and the Lie scale of the Revised Children's Manifest Anxiety scale (RCMAS), one of the most frequently used self-reporting measures in childhood anxiety research (Reynolds \& Richmond, 1985, 1997), consisting of nine items. The latter is derived from the MMPI (Minnesota Multiphasic Personality Inventory) Lie scale and is intended measure impression management. The German version was developed and tested by Boehnke, Silbereisen, Reynolds, and Richmond (1986). The scale is often used as indicator of SDB (Dadds, Perrin, \& Yule, 1998) or defensiveness for children and adolescents.

\section{Impact Variables and Interpretation of SDB}

SDB has also been shown to vary depending on the setting, the audience, and on socio-economic characteristics of the subject, for example age or gender (e.g. Mummendey, 1981).

In adults, elderly people were reported to show higher SDB scores, especially in the case of women (Ray \& Lovejoy, 2003). In children, the opposite tendency was observed, younger children showing higher Lie scores than older ones (Boehnke et al., 1986), sometimes in connection with an interaction between age and sex, only female or only male Lie scores decreasing (Dadds et al., 1998; Richmond \& Millar, 1984). A general effect of gender was observed by Boehnke et al. (1986) who found 
boys to score higher than girls in a German sample, whereas in a US sample, the opposite was the case (see also Crandall et al., 1965). Age differences in SDB of children were explained by a higher dependency of the latter on the approval of adults during the early years, whereas the decrease in SDB of older children may reflect the desire to attain independence from adults, and instead to obtain acceptance from peers or the adolescent subculture in general (Crandall et al., 1965). Others pointed to the higher cognitive development of older children, increasing their ability to report correctly their own actual behaviour compared to ideal behaviour (Brown \& Kodadek, 1987).

Studies of the effects of education are inconsistent (Mummendey, 1981): Johnson, Fendrich, and Hubbell (2002) found decreasing SDB scores with increasing educational level in adults. A somewhat dated example from the US also reports a negative relationship between SDB and intelligence in children (Crandall et al., 1965).

In cross-national surveys, mean national scores of social desirability were found to be negatively correlated to wealth and positively to family collectivism (van Hemert, van de Vijver, Poortinga, \& Georgas, 2002). This leads to the interpretation that SDB may express a true adaptation to social norms of less powerful or affluent groups depending on the approval of other people (e.g. Ross \& Mirowsky, 1984). Two interpretations of SDB exist.

Classic interpretation. The classic interpretation assumes that an SDB scale is able to identify people's differential propensity to present themselves favourably. As a consequence, the scale is used to control for these interpersonal differences by excluding high-SDB scorers or partialling out the effect of SDB. Alternative methods of controlling for the effects of SDB are reviewed by Nederhof (1985, see also Paulhus, 1991). For ethical and organisational reasons these techniques cannot always be applied, however, especially in research with children.

True behaviour interpretation. Control is not necessary if the true behaviour interpretation is applied. It assumes that people who score highly on tests of SDB do in fact behave in an altruistic manner, are conscientious, adjusted, etc. Support for the second idea is given, for example by McCrae and Costa (1983) and by Furnham (1986). The latter proposes that SDB may measure a disposition which overlaps positively or negatively with the other test, for example a need for approval or social naiveté. In the case of pro-environmental attitude and behaviour this would mean that a person does not fake a good impression but really holds the reported attitude and does behave in an eco-friendly way.

Fisher and Katz (2000) point out that the degree to which value self-reports are influenced by SDB also reflects the relative importance of values within a culture. Thus, irrespective of a potential reduction of validity of EA and behaviour measures, a low SDB effect may point to a lack of relevance of environmental issues in a specific country. The effect of SDB on EA and behaviour will be discussed in the following section. 


\section{The Impact of SDB on EA and Ecological Behaviour}

Both EA and ecological behaviours have been suspected of being biased by SDB (e.g. Ewert \& Baker, 2001; Scott \& Willits, 1994). Corresponding results for attitudes have been reported by Schahn (2002) who examined by expert rating the influence of SDB on attitude items. In multiple regressions, the rated SDB explained $25-35 \%$ of the variance in item mean scores. Schahn found no effect of SDB ratings on behaviour item means. Small but inconsistent effects of individual Lie scores on self-reported ecological behaviour were described, for example by Kaiser and co-workers (e.g. Kaiser, 1998; Kaiser et al., 1999). To our knowledge no studies have analysed the influence of SDB on the self-reported ecological behaviour of children.

Ganster, Hennessey, and Luthans (1983) described three alternative consequences of using SDB contaminated measures in behaviour research: The first is misleading correlations between variables (spuriousness), if both variables are correlated with SDB. This would produce an overestimation of the relationship between EA and behaviour. The second is suppression, the masking of relationships between variables because of SDB contamination in one or both of the measures. This was suspected, for example by Ewert and Baker (2001) as an explanation for low correlations between actual behaviour and-potentially biased-EA. Hines et al. (1987), on the other hand, reported in their meta-analysis higher attitude-behaviour correlations when actual behaviours were assessed $(r=0.43)$ than those obtained when selfreported behaviour means were reported $(r=0.33)$. These findings may point to an SDB contamination of self-reported behaviour measures, resulting in a masking of attitude-behaviour relationship. A third possibility is a moderating or interaction effect, if the relationship between two variables differs depending on the size of SDB scores. Possible is a higher correlation between EA and behaviour for high-SDB scorers, compared to low-scorers, if both attitude and behaviour are positively related to social desirability. Schahn (2002) analysed the validity (correlation between assessment by self and others) and reliability of EA and behaviour items on different SDB levels and no moderating effect of expert rated SDB. We are not aware of research testing moderator effects of SDB on the relationship between EA and behaviour.

\section{Objectives}

Though self-reported ecological behaviour and EA are often suspected of failing to provide valid measures due to SDB, only a few studies have shown a substantive effect of SDB. The evidence for children in particular is unclear. Our study focused on an application of a Lie scale for children in the context of EA and self-reported GEB. Our special interest was to check whether attitude and self-reported behaviour scores are inflated by SDB, controlling for socio-demographic and socio-cultural characteristics. We also tested whether SDB affects the attitude-behaviour relationship, masking it, inflating it, or moderating it in a multiple regression analysis. This 
included an exploration of whether Lie scores vary as a function of socio-demographic and socio-cultural characteristics such as gender, age, and stratification levels at school.

\section{Method}

\section{Participants}

Data were gathered from a convenience sample of 5 th and 6th graders in Bavaria ( $N$ $=218$ ). Due to missing data, 20 pupils were excluded. Of the remaining 198 children, $46 \%$ were girls, the mean age was $M=11.52, S D=0.79$. About $50 \%$ of the sample consisted of pupils from classes of the highest stratification, the Gymnasium, referred to as A-level; the others of medium stratification classes, the Realschule, referred to as B-level, both coming from rural communities with less than 50,000 residents. The participants in this inquiry represented the control group of an intervention study, not receiving any intervention. Before administration of the questionnaire, pupils were assured of their anonymity and were requested to answer the scales on their own, but they were not physically separated.

\section{Materials}

Assessment of ecological values. To measure ecological values we applied the 2-MEV model quantifying Preservation and Utilisation (Bogner \& Wiseman, 2006). The Preservation measure consisted of eight items (e.g. 'I enjoy trips to the countryside'), the Utilisation measure consisted of 11 items (such as 'Human beings are more important than other creatures.'). The items of both scales were presented in random order. The response scale ranged from 1 ('totally incorrect') to 5 ('totally correct') including an 'undecided' category.

Assessment of General Ecological Behaviour (GEB). General ecological behaviour was measured using the GEB scale (Kaiser et al., 2007) consisting of 40 items (e.g. 'I separate waste' or 'I buy beverages in cans') covering six domains: energy conservation, mobility and transportation, waste avoidance, consumerism, recycling, and vicarious behaviours towards conservation. Most of the items were answered on a five-point Likert scale from 'always' to 'never', since for behaviours like buying beverages in cans it is easier to give information about frequency than to give a 'yes or no' answer. Since, however, participants were found to be inconsistent in using the more diverse response alternatives (Kaiser \& Wilson, 2000), in line with previous scale calibrations (e.g. Kaiser \& Wilson, 2004) the response format was collapsed to a dichotomous one with 'often' and 'always' as positive responses and 'never', 'seldom', and 'sometimes' as negative ones. Seven items, such as being a member of an environmental organisation, were examined from the outset using a dichotomous format (yes or no). For all items 'I don't know' was a response alternative when an answer was not possible. Such responses were treated as missing values. 
Assessment of SDB. To avoid overstraining pupils with too many items, the German version of the RCMAS Lie scale for children was applied. It consisted of nine very implausible claims, for example 'I never lie' or 'I like everyone I know' (Boehnke et al., 1986) that were placed at the end of the questionnaire. Sum scores between zero (very low SDB) and nine (very high SDB) were possible.

\section{Results}

\section{Lie Scale}

For the Lie scale, Cronbach's alpha was 0.82. The Lie scores were right skewed due to a floor effect, almost one-third of the pupils not agreeing with any of the items. Although we were aware of the violation of assumptions, we decided to use the full range of the Lie scores in multiple regression analyses instead of splitting the scale, and thus loosing information and power as has been criticised by MacCallum and colleagues (MacCallum, Zhang, Preacher, \& Rucker, 2002). The effects of gender and stratification level were tested with the dummy variables female and A-level. To test a potential interaction between age and stratification level, the cross-product between age and A-level was created.

The overall Lie score mean of $M=2.90$ ( $S D=2.57$ ) for our sample is similar to the mean of the German 5th class sample of Boehnke et al. (1986) of $M=2.97$. In a first model, a hierarchical regression analysis as described by Tabachnick and Fidell (1989) yielded no gender effect in Lie scores, girls $(M=2.89, S D=2.61)$ and boys $(M=2.92, S D=2.55)$ showing almost identical mean scores, but a negative effect of age, younger pupils showing higher Lie scores than older ones. This effect explained about $6 \%$ of total variance. In a second model, including the variable A-level (see Table 1), the prediction of Lie scores gained about $9 \%$ of explained variance. The effect of age disappeared, B-level pupils on average being 7.4 months older than Alevel ones. However, no interaction effect was found for A-level and age.

Table 1. Summary of hierarchical regression analysis for variables predicting Lie scores ( $N=194-198)$

\begin{tabular}{|c|c|c|c|c|}
\hline Variable & $B$ & $S E B$ & $\beta$ & \\
\hline \multicolumn{5}{|l|}{ Model 1} \\
\hline Female & -0.12 & 0.36 & -0.02 & \\
\hline Age & -0.83 & 0.23 & $-0.26^{\star \star \star}$ & \\
\hline$R^{2}$ & & & & $.064^{\star \star}$ \\
\hline \multicolumn{5}{|l|}{ Model 2} \\
\hline Female & 0.39 & 0.36 & 0.08 & \\
\hline Age & -0.26 & 0.25 & -0.08 & \\
\hline A-level & 1.83 & 0.40 & $0.36^{\star \star \star}$ & \\
\hline$\Delta R^{2}$ & & & & $.089^{\star \star \star}$ \\
\hline
\end{tabular}

${ }^{\star \star} p<.01,{ }^{\star \star \star} p<.001$. 
The positive regression coefficient indicates the Lie scores of A-level pupils, $M=$ $3.88, S D=2.62$, to be significantly higher than those of B-level pupils with $M=$ $1.95, S D=2.14$.

\section{Environmental Values and General Ecological Behaviour (GEB)}

One item was discarded from the Preservation (P) scale due to inappropriate itemtotal correlation (0.12). For the remaining seven items, the Cronbach's alpha was 0.78 (and 0.77 for the Utilisation (U) scale). In a principal axis factor analysis with Varimax rotation, the two-factor solution explained $30.7 \%$ of variance (cross loadings to the Utilisation scale were few but reached -0.42). The mean for Preservation of $3.84(S D=0.68)$ indicated a general agreement, whereas the Utilisation mean of $2.43(S D=0.63)$ indicated moderate disagreement.

GEB was calibrated as a Rasch scale (for further details see Kaiser et al., 2007). The item scores, indicating the difficulty of behaviour items, ranged from -3.4 to 4.5 , the value of zero arbitrarily set as the mean $(M=0.0, S D=1.82$, adjusted for measurement error: $S D=1.80)$. The internal consistency of the scale was acceptable, with alpha $=0.81$. The person measures ranged from -2.3 to +3.3 , with a total sample mean of $M=0.10$ ( $S D=0.92$, adjusted for measurement error: $S D=0.82$ ). The person separation reliability, that is the proportion of observed estimate variance being considered true, was also acceptable with $R_{P}=0.78$. For item fit assessment we used mean square (MS) statistics. ${ }^{2}$ All but one item fitted the Rasch scale very well with $M S$ values between 0.80 and 1.20 . The less well fitting item with an $M S$ value of 1.23 was included in the scale.

\section{Impact of SDB on Sets of Environmental Attitudes (EA) and General Ecological Behaviour (GEB)}

In order to check a potential impact of SDB on EA and behaviour scores, we ran three hierarchical multiple regression analyses predicting Preservation, Utilisation and GEB by the variables gender, age, and stratification level in a first step (see Model 1 in Table 2) and then adding Lie scores as a predictor in a second step as is shown in the Model 2 in Table 2. The table shows that after controlling for gender, age, and stratification level, the Lie scores are highly significant predictors of Preservation and GEB scores, but not of Utilisation scores. Whereas the inclusion of the Lie scale explains $8 \%$ of additional Preservation variance, it explains only $3 \%$ of additional GEB variance. Both Preservation and GEB are positively related to attendance at an A-level school. This A-level effect disappears in favour of the social desirability effect, whereas the positive effect of A-level on GEB becomes significant also if Lie scores are included.

In our model, by controlling for socio-economic variables, we exclude all Lie scale variance that is related to these variables. Squared zero order correlations, representing the Lie score impact on attitudes and behaviour including age, gender, and stratification level specific variance, yielded $13.8 \%$ of explained Preservation variance $(r=$ $0.372, p<0.001)$ and $10.6 \%$ of explained GEB variance $(r=0.325, p<0.001)$. 


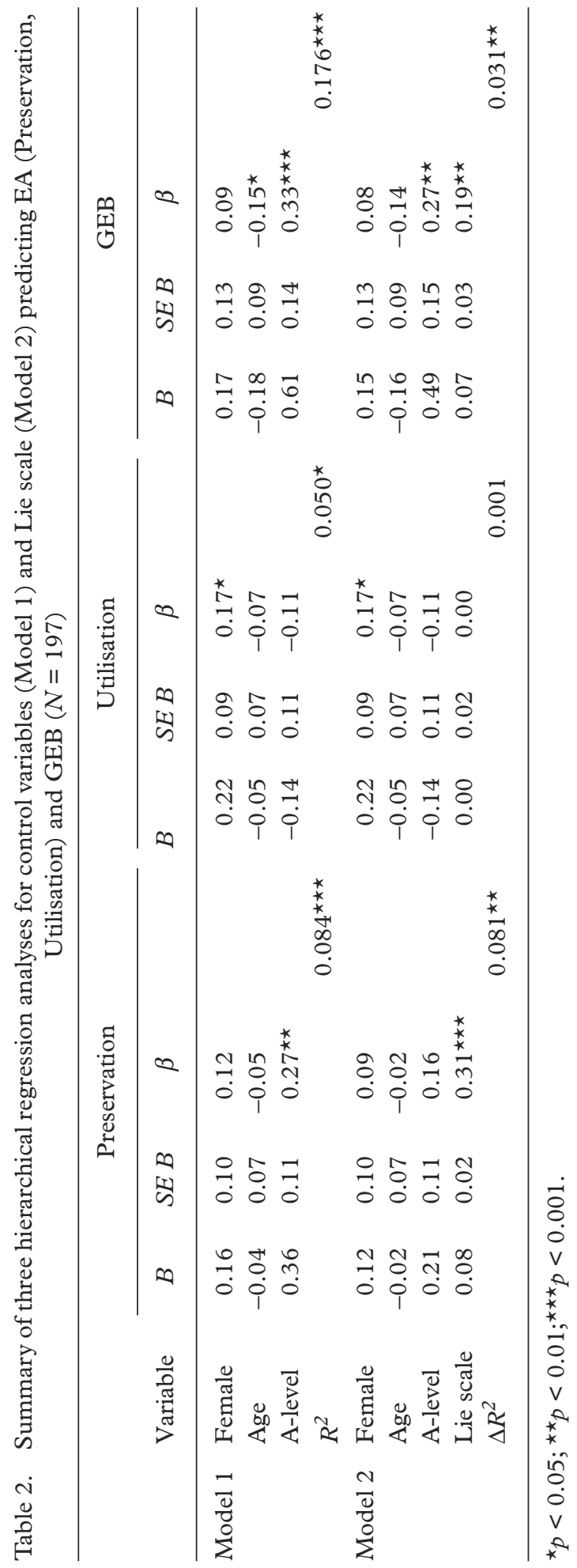


Still, the Lie scale impact on Preservation is higher than that on GEB, despite the fact that the Lie score impact related to age, gender and stratification level is higher for GEB (7.5\%) than for for Preservation $(5.7 \%) .^{3}$

\section{Predicting GEB by Means of Environmental Values and Lie Scores}

One goal of this study was to re-examine the relationship between attitude sets and self-reported behaviour after correction for the Lie scores. Besides a general inflation or masking of the relationship between attitude and behaviour measures, a moderating effect of SDB is also of interest. Therefore, using hierarchical regression analyses (see Table 3) we controlled for the effects of Lie scores and interaction terms ${ }^{4}$ in a first and second model and predicted GEB by Preservation and Utilisation in a third step. ${ }^{5}$

No significant interaction occurred (Model 2, Model 3), either between Lie scores and Preservation or between Lie scores and Utilisation. Thus, SDB has no moderating effect on the relationship between EA and behaviour. Including EA increases the $R^{2}$ by 0.21 , that is $21 \%$ of explained variance. Thus, after controlling for social desirability effects, there is still a Preservation effect on GEB of beta $=0.48$. Considering the correlation between Preservation and GEB of $r=0.544(p<0.001$, according to $29.6 \%$ of explained variance), the impact on GEB is somewhat reduced (by ca. $9 \%$ ).

Note that Utilisation does not improve the prediction of the behaviour scores when included together with Preservation, even though it correlates $r=-0.221$ ( $p$ $<0.01$ ) with GEB. This relationship with behaviour is apparently limited to the variance Utilisation shares with Preservation.

Table 3. Summary of hierarchical regression analysis for EA (Preservation and Utilisation) predicting GEB, after excluding the effects of Lie scores and the interaction of Lie scores with attitudes $(N=194)$

\begin{tabular}{lcccc}
\hline Variable & $B$ & $S E B$ & $\beta$ & \\
\hline Model 1 & & & & \\
$\quad$ Lie scores (L) & 0.12 & 0.02 & $0.33^{\star \star \star}$ & \\
$R^{2}$ & & & & \\
Model 2 & & & $0.33^{\star \star \star \star}$ & \\
$\quad$ Lie scores & 0.12 & 0.02 & -0.05 & \\
$\quad$ Preservation $\times \mathrm{L}$ & -0.03 & 0.04 & 0.03 & \\
Utilisation $\times \mathrm{L}$ & 0.02 & 0.04 & & \\
$\Delta R^{2}$ & & & & \\
Model 3 & & & $0.14^{\star}$ & \\
Lie scores & 0.05 & 0.02 & 0.02 & \\
P $\times$ L & 0.01 & 0.04 & 0.01 & $0.205^{\star \star \star}$ \\
U $\times$ L & 0.01 & 0.04 & -0.04 & \\
Preservation $(\mathrm{P})$ & 0.64 & 0.10 & & \\
Utilisation $(\mathrm{U})$ & -0.06 & 0.09 & & \\
$\Delta R^{2}$ & & & & \\
\hline
\end{tabular}

${ }^{\star} p<0.05 ;{ }^{\star \star \star} p<0.001$. 
We conclude that the impact of Lie scores is higher on Preservation than on GEB, especially when the age and stratification level is taken into account; it is not significant at all for Utilisation. The inclusion of Lie scores neither improves the prediction of GEB by environmental attitude sets nor moderates it significantly, but diminishes it by $8 \%$ of variance shared with the Lie scores.

\section{Discussion}

\section{Moderators and Interpretation of the Lie Scores}

The aim of this study was to identify a potential contamination of EA and selfreported ecological behaviour data of children by SDB. By controlling for potential moderators of Lie scores, we found that older children scored lower than younger ones, but detected no gender effect in the first step, which is consistent with earlier studies (see Dadds et al., 1998; Richmond \& Millar, 1984). However, when in a second step the stratification variable A-level was included, age had no significant effect, which is caused by the confusion of age and stratification level.

The clear effect of stratification level, explaining $9 \%$ of additional variance, is somewhat unusual as A-level pupils score higher on the Lie scale than B-level pupils, which is inconsistent with earlier studies. Plausible impact factors for this A-level effect, such as parents' educational level and the individual's intelligence, point to the opposite effect (see Section 'Impact Variables and Interpretation of SDB'), revealing significantly higher scores for less intelligent children as well as for children with parents of lower socio-economic status.

One explanation may be that our sample was rather small and not representative for Bavaria. Oberwittler and Naplava (2002) provide a second possible explanation: they analysed investigation methods in youth surveys of delinquency. They pointed to different, in part, converse norms and evaluation standards for SDB in different population samples, especially in youth subcultures. A shortcoming in anonymity in normal classroom questioning may, therefore, lead to a context effect. Thus, in classes with pro-social group norms, possibly in A-level classes, respondents would exaggerate their pro-social behaviour, whereas in classes with less pro-social group norms, for example in B-level classes, respondents would understate their SDB, playing the bad boy or the bad girl. This would lead to higher homogeneity inside classes and school forms. This view is speculative but consistent with the interpretation of SDB by Fisher and Katz (2000) that the impact of SDB on a particular value points to the societal importance of the latter.

\section{Impact of Social Desirability on Environmental Values and GEB}

Our results suggest that SDB has an impact on sets of EA and self-reported behaviour: A small to medium correlation was found between Lie scores and Preservation as well as GEB. After controlling for some socio-economic nuisance variables, the Lie scores still show significant effects on Preservation and GEB, explaining an 
additional $8 \%$ of unique Preservation variance, and an additional 3\% of unique behaviour variance. In ecological behaviour, a higher portion of SDB is related to age or stratification level than in Preservation attitudes. Shared variance between stratification level and Lie scale reduces the impact of A-level on GEB to beta = 0.27 . Social desirability is, however, not the only impact factor increasing GEB of Alevel pupils. Environmental values, too, may be of importance, although, after including Lie scores, the tendency towards higher Preservation scores in A-level pupils disappears. Furthermore, the educational level of parents, though in this case not decreasing SDB, may indeed increase their children's ecological behaviour score (e.g. Hines et al., 1987; Scott \& Willits, 1994).

According to Fisher and Katz (2000), the lack of impact of Lie scores on Utilisation points to a dearth of social norms in pupils that may favour agreement or disagreement with Utilisation items. The mean score of about 2.4, indicating an almost neutral position and the non-skewed distribution of the Utilisation factor, confirm this interpretation. A reason might be that single Utilisation items might be difficult for 11-year-old children, for example the statement that our planet has unlimited resources. On the other hand, the scale was developed for adolescents, so such problems should have been apparent at an earlier date.

Compared to earlier findings, the SDB impact in our study was relatively high: Kaiser and colleagues (Kaiser, 1998; Kaiser et al., 1999) found SDB to explain only $1 \%$ of GEB variance. They, however, analysed adult data, and as the SDB of children has been shown to decrease with increasing age (see Section 'Impact Variables and Interpretation of SDB'), the impact of SDB on adult attitudes and behaviours may generally be smaller than that on children. Schahn (2002), however, reported an impact of SDB only on attitude but not on behaviour. He interpreted this result as a hint that self-deception and not others deception was measured and that it was easier to adapt attitude as a consequence of perceived pressure due to SDB than to adapt behaviour. A similar pattern of social desirability effect in adults was found by Milfont (2009) who analysed psychology students in a study like ours, using different Preservation, Utilisation, and ecological behaviour measures as well as an impression management scale for adults.

Like in the present study, he reported no effect of social desirability on Utilisation. However, like Schahn (2002), but in contrast to us, he found ecological behaviour to be not related to social desirability, using a behaviour scale of only eight items. In his study, the correlation of SDB with Preservation $(r=0.12)$ was smaller than in the present study with children $(r=0.37)$; only the correlation with the Preservation subscale, Personal Conservation $(r=0.24)$, had a similar magnitude.

However, to what extent does this SDB impact on environmental attitude sets, and behaviour bias the interrelationship between both?

\section{Removing the Effects of SDB: Impact on the Attitude-Behaviour Relationship}

Controlling for SDB, the impact of Preservation on behaviour is reduced to $21 \%$ of explained variance, that is a still large connection between attitude and behaviour. 
According to Ganster et al. (1983), the reduction points to a spurious correlation caused by shared variance of both variables with SDB, in this case identified to be as large as 9\% (see Section 'Predicting GEB by Means of Environmental Values and Lie Scores'). Neither a masking of the relationship between GEB and Utilisation by SDB nor any moderator effect of the Lie scores was found. That is, the impact of social desirability on ecological behaviour is the same for people with low, as well as high, agreement with Preservation or Utilisation items, which is consistent with Schahn (2002) as well as with Milfont (2009).

Notably, Utilisation does not add to explained behaviour variance. This is comparable to the results of Milfont and Duckitt (2004) who found their Utilisation factor to be correlated with economic liberalism but not with self-reported behaviour. They assume that behaviour may be related to the Utilisation factor, which is more directly linked to the use and consummation of natural resources. In our study pupils do not seem to relate their utilitarian attitude set with their own behaviour.

\section{Conclusions}

According to the results of the present study, the $U$ scale, representing the careless utilisation of natural resources by humans, is not related to social desirability; however, P, representing protection of nature and self-reported behaviour are positively related to SDB. Milfont (2009) came to conclude that social desirability concerns do not have a strong effect on the way people respond to questions addressing environmental issues. We agree that the effect sizes of the prediction of ecological behaviour are at most moderate. Besides the fact that the relationship between attitude and behaviour is not affected by SDB is a very important finding.

However, we disagree that socially desirable responses are not a problem in measures assessing EA and self-reported ecological behaviours. It seems that in young children, the effect is of larger size than in adults. In research with children, we have to consider that due to social desirability, Preservation, and ecological behaviour scores are increased. In older children or youth there might be a contrary effect caused by their wish 'to appear cool'. The types of school or levels of education have had an impact on the agreement with Preservation and behaviour items which seems to be at least in part an effect of social desirability. The parents' socioeconomic status may also play a role (Milfont, 2009). Because we know little about the impact of these aspects on SDB in children, these aspects need to be analysed in further studies.

Some limitations have to be considered. First, the sample is not representative for the general population of pupils, especially given the narrow range of ages.

Second, a Lie scale can give information not only about whether the respective attitude or behaviour is socially desirable for children, but also about the differential tendency of children to adapt their attitude and behaviour reports to the desired norm. That is, at least a part of these reports may not indicate measurement error, but point to actual adaptation of attitudes and behaviour to this norm. 
Moreover, the baseline of the Lie scale is unclear: a score of zero may represent either the absence of social desirability or may imply some kind of negative effect causing children to understate their own pro-social, or in this case pro-environmental, behaviour. According to Schahn (2002) up to now, true attitude is not visible. Nederhof (1985) may be correct when he describes the Marlow-Crowne scale as 'not fit to predict the exact frequency of undesirable behaviour, but may be used to give an indication of the extent to which people distort their reports about a particular behaviour or attitude in a socially desirable direction' (p. 266). By assuming that a part of SDB points to actual attitudes or behaviour, our results can offer an idea of the maximum SDB impact on environmental attitude and behaviour scales, but do not give the true and absolute impact. Thus, as Fisher and Katz (2000) advised, the SDB component should not be removed from self-reported values since a correction may reduce validity.

To conclude, the most important finding of the present study is that the relationship between attitude and behaviour in environmental issues is not distorted by social desirability. The effect size of the Preservation measure and of ecological behaviour is increased nonetheless to some extent. This should be considered when interpreting the outcomes of environmental issue research with children. It seems advisable to apply control scales also in further studies to learn more about the actual amount of SDB impact. This seems important, especially if groups of children with different tendencies to answer in a socially desirable way are compared, for example groups of different ages or from different types of school or socio-economic background.

\section{Acknowledgements}

The study was supported by the University of Bayreuth. First, we appreciate the cooperation of all the students and teachers who participated in this study. Second, we are very grateful to Florian Kaiser and Michael Wiseman for reading and commenting the manuscript.

\section{Notes}

1. Values were corrected for errors due to sampling and due to differences in reliabilities of the measurement instruments.

2. As fit statistic, the averaged mean square $(M S)$ statistics of 0.90 corresponds to a $10 \%$ lack of variation and a $M S$ of 1.10 to a $10 \%$ excess of variation (underfit) in the model prediction compared to what is in the data.

3. The amount of Preservation and GEB variance that is explained both by Lie score and age, gender, and stratification level is consistent with the difference between the explained variance calculated by means of correlations and the one in Model 2 .

4. To avoid multicollinearity in regression analysis with interaction terms (see Tabachnick \& Fidell, 2007), we created centred independent variables.

5. We did not include background variables to avoid that common variance with age, gender, or stratification level is not attributed to Lie scores. 


\section{References}

Ajzen, I., \& Fishbein, M. (1977). Attitude-behaviour relations: A theoretical analysis and review of empirical research. Psychological Bulletin, 84, 888-918.

Bamberg, S., \& Möser, G. (2007). Twenty years after Hines, Hungerford, and Tomera: A new meta-analysis of psycho-social determinants of pro-environmental behaviour. fournal of Environmental Psychology, 27, 14-25.

Boehnke, K., Silbereisen, R. K., Reynolds, C. R., \& Richmond, B. (1986). What I think and feel: German experience with the revised form of the Children's Manifest Anxiety Scale. Personality and Individual Differences, 7, 553-560.

Bogner, F. X., \& Wiseman, M. (1999). Towards measuring adolescent environmental perception. European Psychologist, 4, 139-151.

Bogner, F. X., \& Wiseman, M. (2002). Environmental perception: Factor profiles of extreme groups. European Psychologist, 7, 225-237.

Bogner, F. X., \& Wiseman, M. (2006). Adolescent's attitudes towards nature and environment: Quantifying the 2-MEV model. Environmentalist, 26, 231-237.

Bond, T. G., \& Fox, C. M. (2007). Applying the Rasch model: Fundamental measurement in the human sciences. Mahwah, NJ: LEA.

Brown, M. S., \& Kodadek, S. M. (1987). The use of Lie scales in psychometric measures of children. Research in Nursing and Health, 10, 87-92.

Crandall, V. C., Crandall, V. J., \& Katkovsky, W. (1965). A children's social desirability questionnaire. Fournal of Consulting Psychology, 29, 27-36.

Crowne, D. P., \& Marlowe, D. (1964). The approval motive: Studies in evaluative dependence. New York, NY: John Wiley.

Dadds, M. R., Perrin, S., \& Yule, W. (1998). Social desirability and self-reported anxiety in children: An analysis of the RCMAS Lie scale. Fournal of Abnormal Child Psychology, 26, 311-317.

Diekmann, A., \& Preisendörfer, P. (1998). Environmental behaviour: Discrepancies between aspirations and reality. Rationality and Society, 10, 79-102.

Diekmann, A., \& Preisendörfer, P. (2003). Green and greenback. The behavioural effects of environmental attitudes in low-cost and high-cost situations. Rationality and Society, 15, 441-472.

Dunlap, R. E., \& Van Liere, K. D. (1978). The 'New Environmental Paradigm': A proposed measuring instrument and preliminary results. Fournal of Environmental Education, 9(4), 10-19.

Dunlap, R. E., Van Liere, K. D., Mertig, A. G., \& Jones, R. E. (2000). Measuring endorsement of the New Ecolgical Paradigm: A revised NEP Scale. Fournal of Social Issues, 56, 425-442.

Ewert, A., \& Baker, D. (2001). Standing for where you sit: An exploratory analysis of the relationship between academics major and environment beliefs. Environment and Behaviour, 33, 687-707.

Fisher, R. J., \& Katz, J. E. (2000). Social-desirabiltiy bias and the validity of self-reported values. Psychology and Marketing, 17, 105-120.

Furnham, A. (1986). Response bias, social desirability and dissimulation. Personality and Individual Differences, 7, 385-400.

Gagnon Thompson, S. C., \& Barton, M. A. (1994). Ecocentric and anthropocentric attitudes toward the environment. Fournal of Environmental Psychology, 14, 149-157.

Ganster, D. C., Hennessey, H. W., \& Luthans, F. (1983). Social desirability response effects: Three different models. Academy of Management fournal, 26, 955-966.

Granzin, K. L., \& Olsen, J. E. (1991). Characterizing participants in activities protecting the environment: A focus on donating, recycling, and conservation behaviours. Fournal of Public Policy and Marketing, 10(2), 1-27.

Hines, J. M., Hungerford, H. R., \& Tomera, A. N. (1987). Analysis and synthesis of research on responsible environmental behaviour: A meta-analysis. Fournal of Environmental Education, 18, $1-8$. 
Johnson, T. P., Fendrich, M., \& Hubbell, A. (2002). A validation of the Crowne-Marlowe Social Desirability Scale. Paper presented at the 57th Annual Meeting of the American Association for Public Opinion Research, St. Pete Beach, FL. Retrieved April 1, 2011, from http:// www.srl.uic.edu/publist/Conference/crownemarlowe.pdf.

Kaiser, F. G. (1998). A general measure of ecological behaviour. Fournal of Applied Social Psychology, 28, 395-422.

Kaiser, F. G., Oerke, B., \& Bogner, F. X. (2007). Behaviour-based environmental attitude: Development of an instrument for adolescents. Fournal of Environmental Psychology, 27, 242-251.

Kaiser, F. G., \& Wilson, M. (2000). Assessing people's general ecological behaviour: A crosscultural measure. Fournal of Applied Social Psychology, 30, 952-978.

Kaiser, F. G., \& Wilson, M. (2004). Goal-directed conservation behaviour: The specific composition of a general performance. Personality and Individual Differences, 36, 1531-1544.

Kaiser, F. G., Wölfing, S., \& Fuhrer, U. (1999). Environmental attitude and ecological behaviour. Fournal of Environmental Psychology, 19, 1-19.

Leeming, F. C., Dwyer, W. O., Porter, B. E., \& Cobern, M. K. (1993). Outcome research in environmental education: A critical review. Fournal of Environmental Education, 24, 8-21.

MacCallum, R. C., Zhang, S., Preacher, K. J., \& Rucker, D. D. (2002). On the practice of dichotomization of quantitive variables. Psychological Methods, 7, 19-40.

McCrae, R. R., \& Costa, P. T. (1983). Social desirability scales: More substance than style. Fournal of Consulting and Clinical Psychology, 51, 882-888.

Meinhold, J. L., \& Malkus, A. J. (2005). Adolescent environmental behaviours: Can knowledge, attitudes, and self-efficacy make a difference? Environment and Behaviour, 37, 511-532.

Milfont, T. L. (2009). The effects of social desirability on self-reported environmental attitudes and ecological behaviour. The Environmentalist, 29, 263-269.

Milfont, T. L., \& Duckitt, J. (2004). The structure of environmental attitudes: A first- and secondorder confirmatory factor analysis. Fournal of Environmental Psychology, 24, 289-303.

Milfont, T. L., \& Duckitt, J. (2006). Preservation and Utilization: Understanding the structure of environmental attitudes. Medio Ambiente y Comportamiento Humano, 7, 29-50.

Mummendey, H. D. (1981). Methoden und Probleme der Kontrolle sozialer Erwünschtheit [Methods and problems of social desirability control]. Zeitschrift für Differentielle und Diagnostische Psychologie, 2, 199-218.

Nederhof, A. J. (1985). Methods of coping with SDB: A review. European fournal of Social Psychology, 15, 263-280.

Newhouse, N. (1990). Implications of attitude and behaviour research for environmental conservation. Fournal of Environmental Education, 22, 26-32.

Oberwittler, D., \& Naplava, T. (2002). Auswirkungen der Erhebungsverfahren bei Jugendbefragungen zu 'heiklen' Themen-Schulbasierte schriftliche Befragung und haushaltsbasierte mündliche Befragung im Vergleich [Consequences of investigation methods in youth surveys concerning delicate topics - school-based written questioning in comparison to householdbased oral questioning]. ZUMA Nachrichten, 51(26), 29-77.

Paulhus, D. L. (1984). Two-component models of socially desirable responding. Fournal of Personality and Social Psychology, 46, 598-609.

Paulhus, D. L. (1991). Measurement and control of response bias. In J. P. Robinson, P. Shaver, \& L. S. Wrightsman (Eds.), Measures of personality and social psychological attitudes (pp. 17-59). San Diego, CA: Academic Press.

Paulhus, D. L. (2002). Socially desirable responding: The evolution of a construct. In H. I. Braun, D. N. Jackson, \& D. E. Wiley (Eds.), Psychological and educational measurement (pp. 49-69). Hillsdale, NJ: Erlbaum.

Ray, J. J., \& Lovejoy, F. H. (2003). Age-related social desirability responding among Australian women. Fournal of Social Psychology, 143, 669-671. 
Reynolds, C. R., \& Richmond, B. O. (1985). Revised children's manifest anxiety scale: Manual. Los Angeles, CA: Western Psychological Services.

Reynolds, C. R., \& Richmond, B. O. (1997). What I think and feel: A revised measure of children's manifest anxiety. Fournal of Abnormal Child Psychology, 25, 15-20.

Richmond, B. O., \& Millar, G. W. (1984). What I think and feel: A cross-cultural study of anxiety in children. Psychology in the Schools, 21, 255-257.

Rokeach, M. (1968). Beliefs, attitudes, and values. San Francisco, CA: Jossey-Bass.

Rokeach, M. (1973). The nature of human values. New York, NY: Free Press.

Ross, C. E., \& Mirowsky, J. (1984). Socially desirable response and acquiescence in a crosscultural survey of mental health. Fournal of Health and Social Behaviour, 25, 189-197.

Sackeim, H. A., \& Gur, R. (1979). Self-deception, other-deception, and self-reported psychopathology. Fournal of Consulting and Clinical Psychology, 47, 213-215.

Schahn, J. (2002). Aufwand und soziale Erwünschtheit als Prädiktoren von Itemmittelwerten: Analysen auf Aggregat- und Individualdatenebene im Bereich Umwelteinstellung und -verhalten [The role of behavioural costs and social desirability as predictors of environmental attitudes and conservation behaviour: An analysis on aggregate and on individual data level]. Zeitschrift für Differentielle und Diagnostische Psychologie, 23, 45-54.

Schultz, P. W., Shriver, C., Tabanico, J. J., \& Khazian, A. M. (2004). Implicit connections with nature. Fournal of Environmental Psychology, 24, 31-42.

Scott, D., \& Willits, F. K. (1994). Environmental attitudes and behaviour: A Pennsylvania survey. Environment and Behaviour, 26, 239-260.

Stern, P. C., Dietz, T., \& Guagnano, G. A. (1995). The New Ecological Paradigm in socialpsychological context. Environment and Behaviour, 27, 723-743.

Tabachnick, B. G., \& Fidell, L. S. (2007). Using multivariate statistics. Boston, MA: Allyn \& Bacon.

Van Hemert, D. A., Van de Vijver, F. J. R., Poortinga, Y. H., \& Georgas, J. (2002). Structural and functional equivalence of the Eysenck Personality Questionnaire within and between countries. Personality and Individual Differences, 33, 1229-1249.

Van Liere, K. D., \& Dunlap, R. E. (1981). Environmental concern: Does it make a difference how it's measured? Environment and Behaviour, 13, 651-676.

Weigel, R., \& Weigel, J. (1978). Environmental concern: The development of a measure. Environment and Behaviour, 10, 3-15.

Wiseman, M., \& Bogner, F. X. (2003). A higher-order model of ecological values and its relationship to personality. Personality and Individual Differences, 34, 783-794. 